\title{
Operational forecasting of a snowfall event over the Greater Athens Area
}

\author{
P. Louka, D. Boucouvala, F. Gofa, M. Balami, and D. Ziakopoulos \\ Hellenic National Meteorological Service, El. Venizelou 14, Hellinikon, 16777, Greece
}

Received: 27 February 2009 - Revised: 30 September 2009 - Accepted: 23 November 2009 - Published: 8 March 2010

\begin{abstract}
A case of an intense snowfall in the Greater Athens Area (GAA) between 16 and 18 February 2008 is investigated. The physical processes that forced the snowfall event are identified and analysed. The main factor causing the event at its start was the entrainment of arctic air masses from North-Eastern Europe. At a second stage, the Aegean Sea acted as the Great Lakes of Canada and North-East USA and in association with the existing extremely cold air masses aloft and the enrichment of the air with humidity and heat led to the enhancement of the snowfall in the GAA. In the final stage of the event, the local meteorological conditions associated with the topography of the area resulted in the occurrence of very intense snowfall event on the leeward side of the GAA. The available operational observations and forecast tools were used for accurately predicting the intensity, duration and evolution of the event.
\end{abstract}

\section{Introduction}

During the period from 16 to 18 February 2008, the Greater Athens Area (GAA) experienced an intense snowfall event causing serious transportation problems. Snow depth reached $10-20 \mathrm{~cm}$ in the centre of the city and $30-50 \mathrm{~cm}$ in the northern suburbs. Even in the port of Piraeus, situated at the south-west part of the GAA, intense snowfall with a snow depth of $\sim 30 \mathrm{~cm}$ was recorded at the end of the period. Such severe weather conditions over the GAA are rare, as on average there are only 0.9 days with snowfall every February (Helliniko station in the southern suburbs of Athens). The intensity of the event is also supported by the low temperatures recorded in the GAA. At Helliniko station, where the average February climatic minimum temperature since

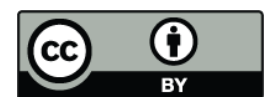

Correspondence to: P. Louka

(louka@hnms.gr)
1955 is $7.1^{\circ} \mathrm{C}$, a value of $-4.2{ }^{\circ} \mathrm{C}$ was recorded in the early morning of 18 February, which is the absolute minimum for that station since 1955. (The previous minimum value up to the event period was $-3.8^{\circ} \mathrm{C}$ measured on 13 February 2004). In the same night, at Philadelphia station (near the centre of Athens) a temperature of $-5^{\circ} \mathrm{C}$ was recorded (mean February climatic minimum $5.4^{\circ} \mathrm{C}$ ). Such an intense snowstorm was recorded during January 2002 and was studied by Lagouvardos et al. (2002).

Hellenic National Meteorological Service (HNMS) operational weather forecasts are based on on-line groundbased and upper air observations from meteorological stations, satellite and radar imagery and model predictions. Specifically, HNMS receives on a daily basis the numerical weather prediction (NWP) products from ECMWF, namely the deterministic forecasts of the ECMWF global model with 0.25 degrees horizontal resolution for the 00:00 UTC and 12:00 UTC cycles and the Ensemble Prediction System (EPS) ECMWF products. All ECMWF forecasts are utilized for providing the operational medium and long-range weather predictions, i.e. greater than 3 days. For the shorter range weather prediction high-resolution NWP products are used. These products help to identify local weather flows influenced for example by topography.

In particular, three different state-of-the-art NWP, run at the premises of HNMS everyday, providing forecasts of up to 72-h. These models are widely known and used in several national meteorological services around the world and are the non-hydrostatic COSMO (based on Lokal Modell LM) (e.g., Steppeler, 2003), SKIRON (based on Eta model) (e.g., Kallos et al., 1997) and RAMS (e.g., Pielke et al., 1992) models. This paper will deal with the COSMO model products.

COSMO (http://www.cosmo-model.org) is a nonhydrostatic fully compressible limited-area atmospheric model. The present version uses Arakawa C-grid with Lorenz vertical grid staggering. The horizontal resolution

Published by Copernicus Publications on behalf of the European Geosciences Union. 
is 0.0625 degrees $(\sim 6 \mathrm{~km})$ and the number of the vertical levels is 60 , with the uppermost level being at $20 \mathrm{hPa}$. A bulk microphysics parameterization is implemented for precipitation formation including water vapour, cloud water, cloud ice, rain and snow with 3-D transport for the precipitating phases, while the Tiedtke (1989) mass-flux convection scheme with equilibrium closure based on moisture convergence is applied for resolving convective precipitation. The parameterisation of the turbulent fluxes is based on a prognostic equation for turbulent kinetic energy and is a level 2.5 closure scheme, while the subgrid-scale turbulent processes are resolved with a 3-D closure scheme (Doms et al., 2007). The COSMO model runs twice a day for the 00:00 and 12:00 UTC cycles using the corresponding initial and boundary conditions from the ECMWF global model and has a forecast horizon of 72 hours.

The purpose of this paper is to determine the physical processes that forced the extraordinary snowstorm event and investigate the efficiency of tools and products available to HNMS for the operational forecasting of the event.

\section{Synoptic analysis}

This event was characterized by significant snowfall even at coastal areas. Three stages were identified during the event. Firstly, upper-level cold air masses were transported towards Greece by a north-easterly flow; at a second stage, the NE flow brought cold air over the warmer Aegean Sea. These two stages led to snow depth of $20-50 \mathrm{~cm}$ over the northern, central and eastern part of the GAA. At the final stage, on 18 February, a local flow was developed due to the local topography resulting in snow depth of $30 \mathrm{~cm}$ over the western and southern part of the GAA.

Prezerakos and Angouridakis (1984) outlined the synoptic conditions necessary for prolonged snowfall over the GAA and classified them into two types: A and B. Type A is characterized by the presence of a strong anticyclone over Western Europe and a field of low pressure over the eastern Mediterranean region, due to a depression invading from the north. Type B is characterized by the presence of a strong anticyclone over Eastern Europe and low pressure system over the eastern Mediterranean Sea including the eastern Greek seas.

In the event under consideration, the case of Type A was identified. The synoptic scale weather pattern on the 16 February revealed a closed $500 \mathrm{hPa}$ low, centred over Ukraine, associated with an elongated trough to the southwest extending from NW Greece (Fig. 1a). Arctic air masses were thus advected from NE Europe, due to a strong NE upper air flow, while at the lower level of $850 \mathrm{hPa}$ the air temperature over the main part of Greece was below zero. On the following day, the trough moved south-westwards with a low centred over the Northern Aegean Sea (Fig. 1b) which was associated with lower temperatures, while at $850 \mathrm{hPa}$, temperature dropped significantly.

At the surface, on 16 February at 12:00 UTC a high pressure system (1048 hPa of ECMWF analysis) existed over Central Europe (Fig. 1b) which had remained stationary for at least the previous $24 \mathrm{~h}$. An extended low pressure system prevailed over the eastern Mediterranean with two centres; one in the Gulf of Sirte (1013 hPa of ECMWF analysis) and one west of Cyprus (1013 hPa of ECMWF analysis). The combination of these two systems resulted in a low-level north easterly flow with mean wind speed of the order of $25 \mathrm{kt}(\approx 13 \mathrm{~m} / \mathrm{s})$ over the Aegean Sea. On the next day, the pressure gradient intensified, as the anticyclone moved towards the Balkans and the low-pressure system west of Cyprus remained almost stationary and deepened (Fig. 1b), causing stronger winds with mean wind speed of $35 \mathrm{kt}(\sim 18 \mathrm{~m} / \mathrm{s})$ over the Aegean Sea. The entrainment of cold arctic air masses of $-30^{\circ} \mathrm{C}$ to $-40^{\circ} \mathrm{C}$, at $500 \mathrm{hPa}$, was the main factor causing the initiation of the event.

At a second stage, the NE winds brought cold air $\left(-10^{\circ} \mathrm{C}\right.$ at $850 \mathrm{hPa})$ over the warmer seawater $\left(14-15^{\circ} \mathrm{C}\right)$. The air above the water moistened, rose and condensed forming cloud bands that moved towards the shores. The forced ascent on the downwind shores enhanced the effect and narrow bands of snow were formed. As land temperatures were low enough (below zero), snow fell and reached the surface. This particular condition is defined here as the "Aegean Snow Effect", which is similar to the "Great Lakes Effect".

Niziol (1984) presented the conditions necessary for similar snow events in region of the Great Lakes in North America known as the "Great Lakes effect" during which: (i) an unstable surface layer extends up to $850 \mathrm{hPa}$ with temperature difference $\left(T_{\mathrm{sfc}}-T_{850}>13 \mathrm{~K}\right)$, (ii) directional wind shear between the Planetary Boundary Layer (PBL) and $700 \mathrm{hPa}$ is less than 30 degrees of azimuth $(30 \mathrm{~N})$ with speeds less than $40 \mathrm{kt}$ and (iii) significant moisture is present between the surface and $700 \mathrm{hPa}$. Wind shear can be detrimental to snow formation as bands become less intense or spread out. Fetch has to be large enough $(>100 \mathrm{~km})$ to provide the PBL with time to become saturated.

The sounding over the southern GAA (Fig. 2a) at 00:00 UTC on 17 February showed $-28.3^{\circ} \mathrm{C},-9.7^{\circ} \mathrm{C}$, and $1{ }^{\circ} \mathrm{C}$ at $500 \mathrm{hPa}, 850 \mathrm{hPa}$ and the surface respectively, and the presence of humid air (relative humidity $70-100 \%$ ) up to $700 \mathrm{hPa}$. The wind speed was $30 \mathrm{kt}(\sim 15.5 \mathrm{~m} / \mathrm{s})$ (i.e., less than $40 \mathrm{kt} ; \sim 20.5 \mathrm{~m} / \mathrm{s}$ ) and there was no significant wind shear between the surface and $700 \mathrm{hPa}$. The lower layer was unstable with $\left(T_{\mathrm{sfc}}-T_{850}\right) \approx 11 \mathrm{~K}$, while $12 \mathrm{~h}$ later the temperature difference was $13.5 \mathrm{~K}\left(T_{\mathrm{sfc}}=1^{\circ} \mathrm{C}, T_{850}=-12.5^{\circ} \mathrm{C}\right)$. Above the sea this temperature difference is expected to have been even more pronounced. Moreover, the fetch is large enough as air travels over the Aegean Sea from North to South before reaching the east coastal areas of the GAA. Thus the conditions for snow-band formation of Niziol (1984) were fulfilled and the enhancement of snowfall 

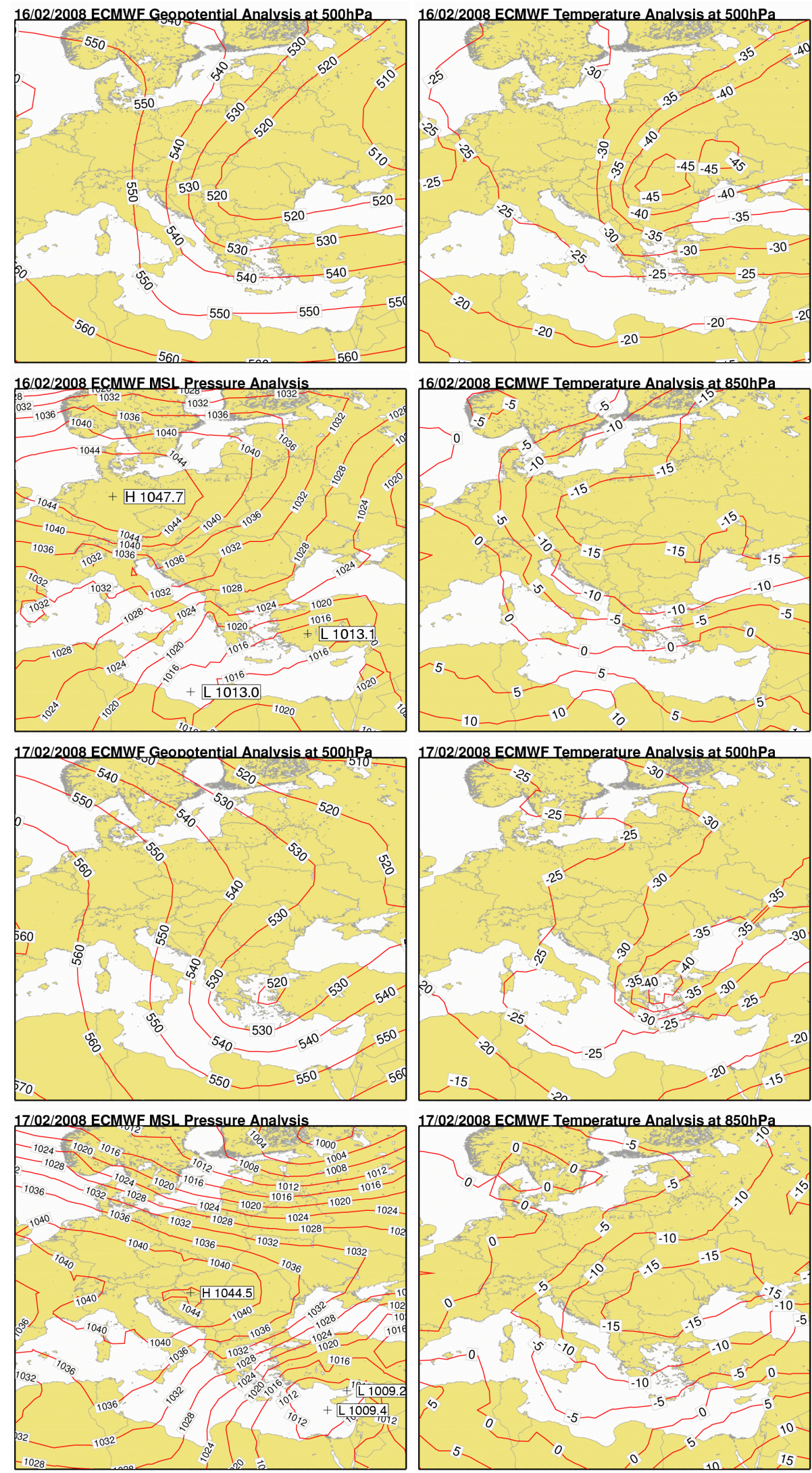

Fig. 1. ECMWF analyses of (a) $500 \mathrm{hPa}$ geopotential height (top-left - contour step of 10 dam is used) and temperature (top-right - contour step of $5^{\circ} \mathrm{C}$ is used), mean sea-level pressure (bottom left - contour step of $4 \mathrm{hPa}$ is used) and $850 \mathrm{hPa}$ temperature (bottom right - contour step of $5{ }^{\circ} \mathrm{C}$ is used) for $16 \mathrm{February} 2008$ at $12: 00 \mathrm{UTC}$ and (b) corresponding plots for 17 February 2008. 
(a)

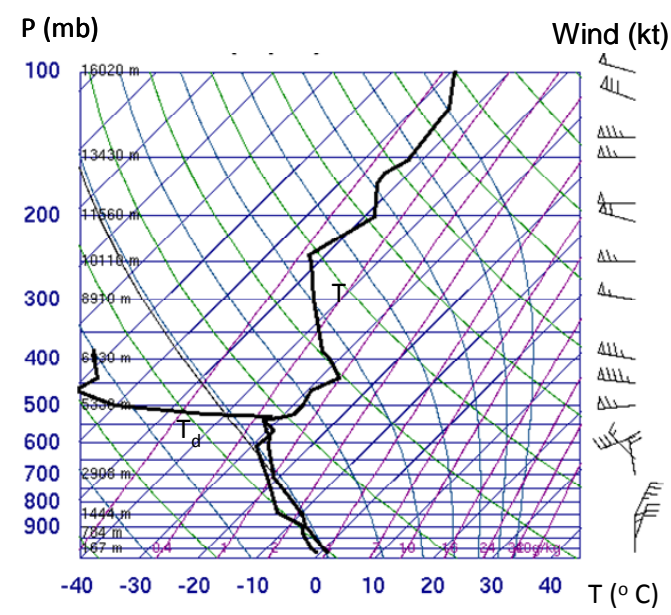

(b)

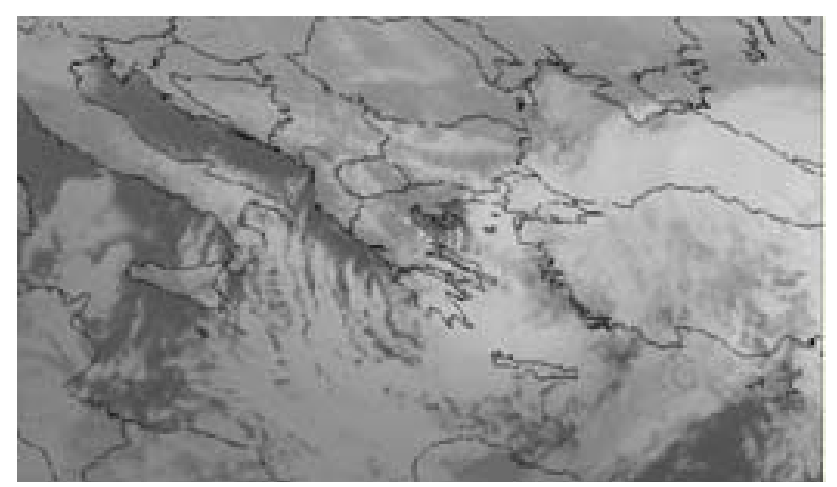

Fig. 2. (a) Sounding at Helliniko station (lon: $23.73^{\circ}$, lat: $37.89^{\circ}$ ) on 17 February at 00:00 UTC (source: University of Wyoming) and (b) infrared satellite image at 06:00 UTC on 17 February (source: Meteosat MSG2).

that occurred over the eastern GAA on 17 February was justified. The infrared satellite image at 06:00 UTC on that day (Fig. 2b) shows the aforementioned cloud bands over the Aegean Sea.

At the final stage of the event, a local flow was forced by the topography resulting in snowfall over the western and southern regions of the GAA. NE winds prevailed over the eastern basin, while NW winds were observed west of the GAA. The combined effect of these two flows was the development of a convergence zone over the western basin, which further helped force humid air upwards, causing the snowfall over the southern and western suburbs of the GAA on 18 February.

\section{Forecasting the event}

The ECMWF EPS of 12 February 12:00 UTC-cycle mean forecast of the geopotential height at $500 \mathrm{hPa}$ for 12:00 UTC
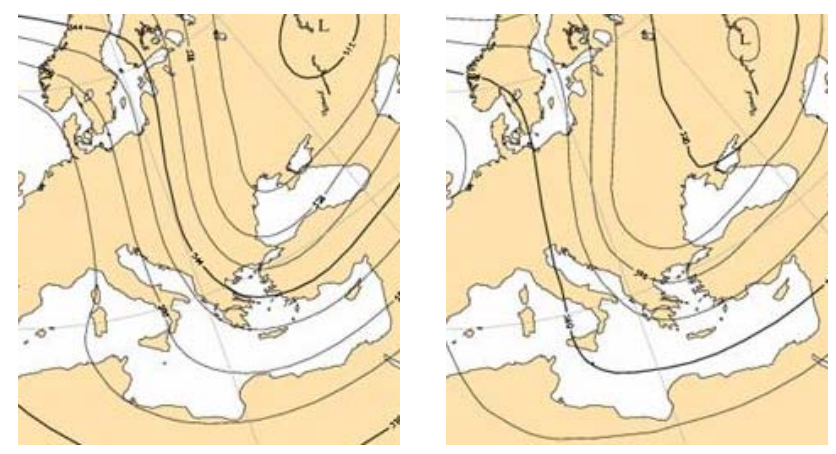

Fig. 3. $500 \mathrm{hPa}$ mean EPS geopotential height contours (contour interval $10 \mathrm{dam}$ ) for 16 February 2008 at 12:00 UTC based on 12 February (left) and 14 February (right) 12:00 UTC-cycle.

on 16 February (Fig. 3) presents a closed low over Ukraine, associated with an elongated trough, which is more extended to the east over NE Greece, compared with the observed situation shown in Fig. 1. This trough leads to a more NW wind flow over the country, which would bring less cold air than a NE flow may have produced. A later forecast, though (14 February, 12:00 UTC-cycle), presents a more realistic distribution of the $500 \mathrm{hPa}$ geopotential height field (Fig. 3). Similar information was obtained using the corresponding deterministic forecasts (not shown).

Several days before the event, ECMWF deterministic and EPS forecasts suggested a large probability of snowfall occurrence over the GAA. The Athens EPSgrams of the 12:00 UTC-cycle forecast on 12 February, i.e. 4 days before the event, showed a trend of decreasing temperature reaching values below $0{ }^{\circ} \mathrm{C}$ during the whole period of the event (Fig. 4). This trend, in combination with the corresponding amount of the EPS precipitation, implied snowfall over Athens during that period. A first estimate of the snowfall distribution was given by the ECMWF deterministic forecast of the 12:00 UTC-cycle run of 14 February, which showed the accumulative snowfall to be intense over the region of Attica (not shown).

The COSMO predictions, three days before the beginning of the snowfall event, i.e. the 12:00 UTC cycle run on 14 February 2008, showed significant snowfall (of the order of $2 \mathrm{~mm}$ cumulative snowfall in $12 \mathrm{~h}$ ) over the GAA (not shown). Nevertheless, this was already predicted by the ECMWF deterministic and EPS forecasts a couple of days before (c.f. Figs. 3 and 4). However, the importance of using high-resolution NWP was supported by the prediction of the local flow that was observed over the western portion of the GAA and had as a result an intense snowfall subevent on 18 February in that area. Figure 5a shows the $10 \mathrm{~m}$ wind field on 18 February at 04:00 UTC, a product of the 12:00 UTC-cycle COSMO run on the 16 February, indicating a local flow characterised by a northwest surface wind in the west and northerlies in the eastern part of the GAA. These 

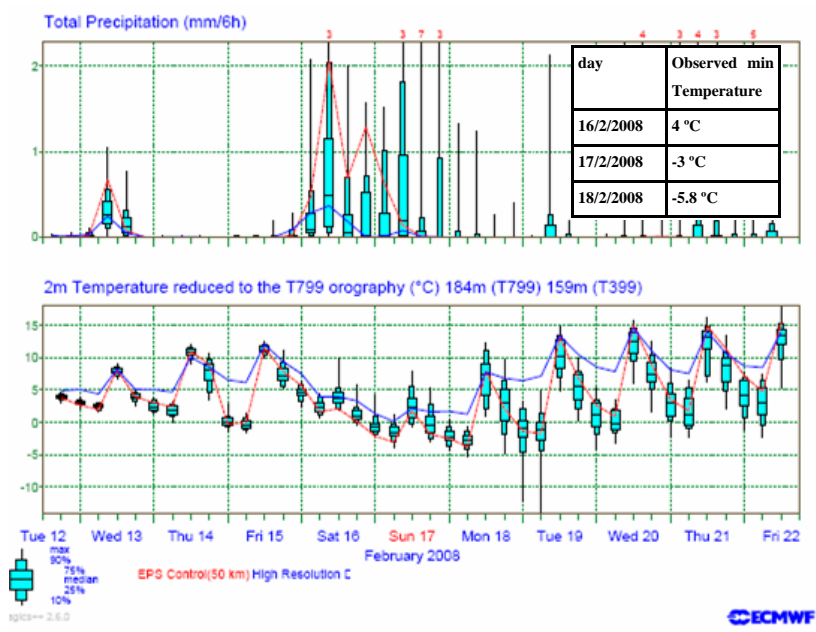

Fig. 4. Athens EPSgram based on 12 February 12:00 UTC-cycle. The red line represents the control run $(50 \mathrm{~km}$ resolution) of the EPS, the blue line represents the deterministic model run $(25 \mathrm{~km}$ resolution), while the bars represent the percentiles of the ensemble prediction. The superimposed table includes indicative minimum temperatures observed in the GAA each day. It is noted that the EPS location for Athens is actually in the south of GAA.

combined flows are similar to those observed, although the predicted surface winds in the eastern basin were northerlies instead of the observed north-easterlies. Nevertheless, the third stage of the event, as discussed in Sect. 2, was well forecast by COSMO. This is supported by the 12-h cumulative snow field (Fig. 5b) indicating snow during 16:00 UTC on 17 February and 04:00 UTC on 18 February over the western, southern and north-eastern parts of Attica.

In order to determine the quality of all the NWP products that were produced or used and to gain insight into their accuracy and usefulness, a verification process is essential. At HNMS, a versatile, automated verification system has been in operation since the end of 2006 in order to provide objective statistics for the performance of the models. The forecast values of weather parameters are compared with synoptic meteorological data from the HNMS operational network of stations and a range of statistical scores is calculated on a daily, monthly and yearly basis. For our study, synoptic data were used from 10 stations (Tanagra, Philadelphia, Tatoi, Helliniko, Piraeus, Elefsina, Spata, OAKA, Kolimvitirio, Rafina) covering an extended area in Attica (Fig. 5a). Even though a list of weather parameters were compared, we focused manly on $2 \mathrm{~m}$ temperature trying to assess the ability of the models to correctly predict the low temperatures that were observed during the snowfall event.

Due to the close proximity of the stations, the verification was performed using comparison between the observation and the closest forecast point, excluding points that are over water. The comparison indicated (Fig. 6) a small overestimation of the mean temperature for all the stations (up (a)

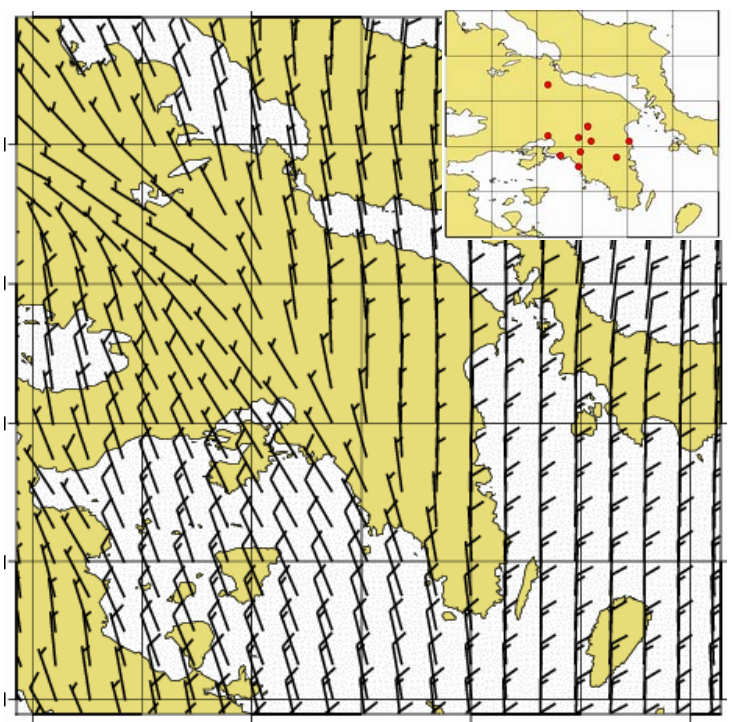

(b)

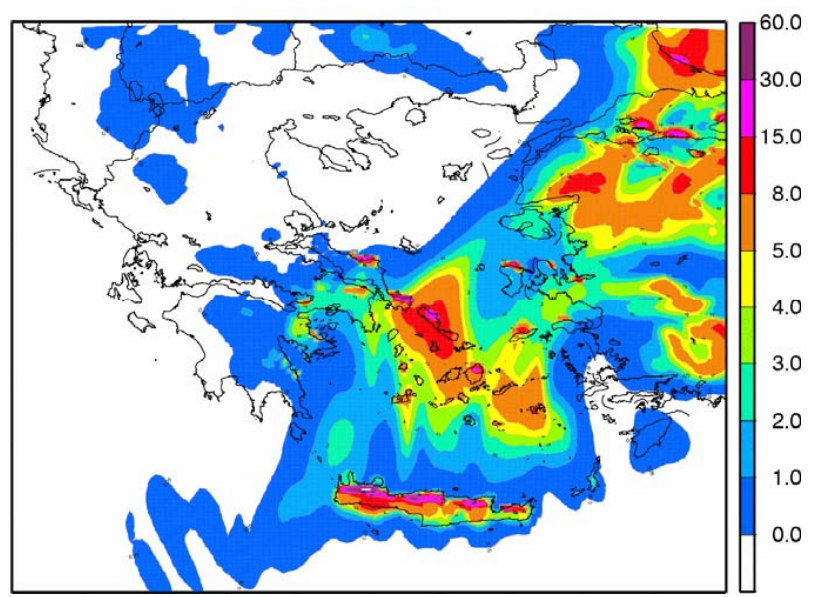

Fig. 5. (a) $10 \mathrm{~m}$ wind field (in kt) (full bar represents $10 \mathrm{kt} ; \sim 5 \mathrm{~m} / \mathrm{s}$, and half bar $5 \mathrm{kt} ; \sim 2.5 \mathrm{~m} / \mathrm{s}$ ) (the red dots in the superimposed image indicate the station locations used for comparison with observations), (b) 12-h accumulative snow field (in mm), on 18 February 04:00 UTC based on 16 February 2008 12:00 UTC-cycle.

to $\left.1.5^{\circ} \mathrm{C}\right)$ for the COSMO model and a quite larger $(\sim 2-$ $5^{\circ} \mathrm{C}$ ) for ECMWF model as it was expected due to its lower horizontal resolution. RMSE values ranged between $2-3{ }^{\circ} \mathrm{C}$ for COSMO and $3-6^{\circ} \mathrm{C}$ for ECMWF model, indicating the importance of the use of local models for the prediction of extreme events.

\section{Conclusions}

The HNMS operational forecast of the snowfall event observed between 16 and 18 February 2008 over the GAA, was 


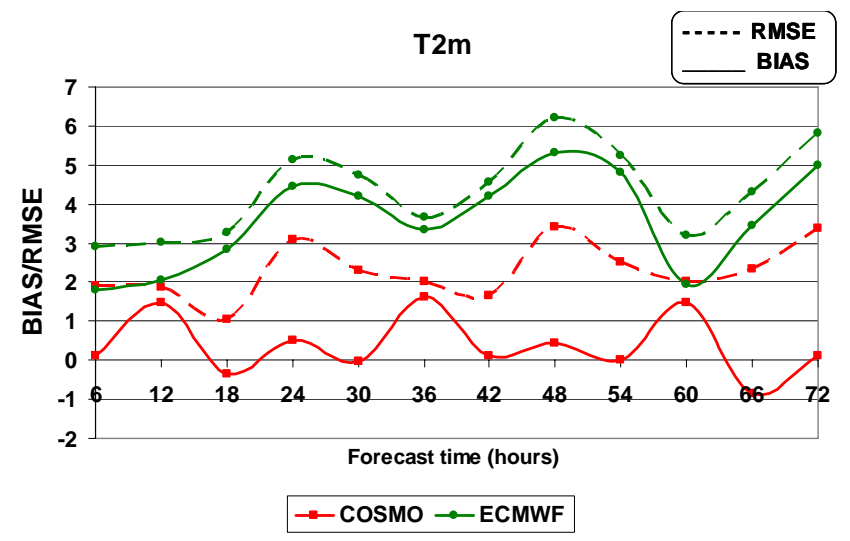

Fig. 6. Average BIAS and RMSE values for $2 \mathrm{~m}$ temperature using data from 10 stations, using the 16 and 17 February 00:00 UTC runs, for both COSMO and ECMWF deterministic models.

based on the available observations and atmospheric models products. Two approaches were used to predict the three stages of the event, depending on the time and space scales; the ECMWF products provided an early alert regarding the occurrence of snowfall, while the COSMO model gave a more detailed prediction of the local circulation and snowfall distribution. The verification of COSMO showed an overestimation of the $2 \mathrm{~m}$ mean temperature, which was smaller than the corresponding values of error for the ECMWF deterministic model statistics.

The "Aegean Snow Effect" needs further investigation as it is the main factor for the generation of intense snowfall events on several parts of Greece, such as eastern central Greece and northern Crete.

Acknowledgements. The authors would like to thank Mr Ioannis Mallas for providing the ECMWF EPSgrams.

Edited by: S. Michaelides, K. Nicolaides, and A. Orphanou Reviewed by: I. Pytharoulis and K. Lagouvardos

\section{References}

Doms, G., Förstner, J., Heise, E., Herzog, H.-J., Raschendorfer, M., Reinhardt, T., Ritter, B., Schrodin, R., Schulz, J.-P., and Vogel, G.: A description of the nonhydrostatic regional model LM - Part II Physical parameterisation, available at: http://www. cosmo-model.org/content/model/documentation/core/, 2007.

Kallos, G., Nickovic, S., Papadopoulos, A., Jovic, D., Kakaliagou, O., Misirlis, N., Boukas, L., Mimikou, N., Sakellaridis, G., Papageorgiou, J., Anadranistakis, E., and Manousakis, M.: The regional weather forecasting system SKIRON: an overview, Proceedings of the International Symposium on Regional Weather Prediction on Parallel Computer Environments, 15-17 October 1997, Athens, Greece, 109-122, 1997.

Lagouvardos, K., Kotroni, V., Fragouli, P., Ziakopoulos, D., and Anadranistakis, M. : The 4-6 January 2002 snowfall: Analysis of the forecast skill of limited area numerical models, Proceedings 6th Hellenic conference on Meteorology, Climatology and Atmospheric Physics, Ioannina 25-28 September, 2002.

Niziol, T. A.: Operational forecasting of lake effect snowfall in western and central New York, Weather Forecast., 2, 310-321, 1984.

Pielke, R. A., Cotton, W. R., Walko, C. J., Tremback, C. J., Lyons, W. A., Grasso, L. D., Nicholls, M. E., Moran, M. D., Wesley, D. A., Lee, T. J., and Copeland, J. H.: A comprehensive meteorological modeling system - RAMS, Meteorol. Atmos. Phys., 49, 69-91, 1992.

Prezerakos, N. and Angouridakis, V.: Synoptic consideration of snowfall in Athens, J. Climatol., 4, 269-285, 1984.

Steppeler, J., Doms, G., Schättler, U., Bitzer, H.-W., Gassmann, A., Damrath, U., and Gregoric, G.: Meso-gamma scale forecasts using the non-hydrostatic model LM, Meteorol. Atmos. Phys., 82, 75-96, 2003.

Tiedtke, M.: A comprehensive mass flux scheme for cumulus parameterization in large-scale models, Mon. Weather Rev., 117, 1779-1799, 1989. 